\title{
Revisión paleográfica de las inscripciones celtibéricas en signario paleohispánico «alfabetizado»
}

\author{
Paleographic review of celtiberic inscriptions in paleohispanic \\ alfabetized signs
}

\author{
Serafín Olcoz Yanguas \\ Manuel Medrano Marqués \\ Universidad de Zaragoza
}

\section{RESUMEN}

Se presenta la revisión paleográfica de los escasos documentos escritos en celtibérico y en los que se emplearon los signos del semisilabario paleohispánico como si de un alfabeto se tratara.

Comprobándose que parte de ellos muestras vestigios de errores tipográficos cometidos por los escribas que los realizaron e incluso de cómo fueron corregidos antes de finalizar la obra y de ser entregada a su destinatario. Estos documentos se han venido considerando como pertenecientes a una etapa del proceso de aculturación latina pero hasta ahora sólo se había catalogado como tales a los que aplicaban esta técnica sistemáticamente, sin considerar que también pudo haberse aplicado de forma parcial o asistemática, como parece que así lo muestran los textos que se revisan a continuación. Además, se destaca el hecho de la presencia de errores cometidos por escribas, que seguramente estaban acostumbrados a escribir por encargo tanto en signario paleohispánico como en alfabeto latino, y se plantea la posibilidad de que, precisamente, su dominio concurrente de ambos sistemas

\begin{abstract}
The aims of this paper is to present a palaeographic review of few documents written in Celtiberian language. Those documents contain signs of the paleohispanic semi-syllabary. It has been confirmed that part of the documents show remains of typographical errors made by the 'writer' as well as remains of the corrections made before the work was over and delivered to its final addressee. Those documents have been considered as belonging to a stage in the process of Latin acculturation but until now, only have been catalogued in this way those that apply this technique over and over without considering that, probably, this technique could have been applied without any order or system. Furthermore, the presence of mistakes made by the scribes is noted. Surely they were used to writing in paleohispanic script as well as in Latin alphabet on request. Also their concurrent fluency on both writing systems can be proposed as a signal of the influence on the aforementioned process of change or adaptation which
\end{abstract}


de escritura tuviera gran influencia en el citado proceso de cambio o adaptación que llevó, primero, al uso alfabetizado del semisilabario celtibérico y, después, a su desaparición y completa susctitución por el alfabeto latino.

\section{PALABRAS CLAVE}

Semisilabario celtibérico, transición al alfabeto latino, paleografía. first led to the use of the Celtiberian semi-syllabary and then to the extinction and replacement with the Latin alphabet.

\author{
KEYWORDS \\ Celtiberian semi-sillabary, transitio to Latin \\ alphabet, paleography.
}

\section{INTRODUCCIÓN}

El celtibérico es una lengua celta, de la familia indoeuropea, y de la que sólo nos han llegado vestigios de su escritura en una variante del semisilabario - combinación entre alfabeto y silabario- o signario ibérico nororiental, cuyos documentos están datados entre el siglo II a.C. y el I o II d.C. Esto es, no hay constancia de su escritura hasta poco después del comienzo de la romanización de la península lbérica y, en su etapa final, se solapó con el subsiguiente proceso de latinización que conllevó la definitiva adopción del alfabeto y de la lengua latina entre los celtíberos, en este orden. Precisamente y aplicando un criterio puramente filológico, se viene considerando como una consecuencia de la influencia cultural latina que afectó al cambio de su sistema de escritura, el hecho de que unas pocas inscripciones fueran escritas en celtibérico y en el citado signario paleohispánico pero utilizándolo como un semisilabario «alfabetizado», al presentar redundancia vocálica o sea al repetir sistemáticamente tras cada signo silábico el signo de la vocal correspondiente. Lo que, además, se viene considerando como una manifestación del paso previo a la adopción generalizada del sistema de escritura y de la lengua latina, por este orden, que sólo se dio en la zona occidental de Celtiberia ${ }^{1}$.

Al decir que sólo son unas pocas las inscripciones celtibéricas que están escritas en signario palehispánico alfabetizado debemos concretar que su número absoluto es sólo de media docena escasa ${ }^{2}$ y que, teniendo en cuenta que el número

\footnotetext{
1 JORDÁN propuso una evolución diferente en las dos zonas geográficas en las que se escribía en celtibérico con la variante oriental o la occidental. De modo que en la primera de ellas se dejaría de usar la lengua celtibérica y la escritura en signario paleohispánico para adoptar directamente la lengua latina y el alfabeto latino mientras que, en la zona occidental de Celtiberia hubo un paso intermedio en el que coexistieron ambas lenguas, cada una con su sistema de escritura, al que debió seguir un período en el que se produjo la alfabetización del signario paleohispánico para escribir en celtibérico antes de que se generalizase completamente el uso de la lengua y el alfabeto latino. Además, citando a Tácito (Annales 4,45 ), recordó que el año 25 d.C. un termestino (Montejo de Tiermes, Soria, Castilla y León) todavía se expresaba en su propia lengua, destacando que se trataba de una ciudad ubicada en la zona occidental. JORDÁN 2007, pp. 138-139.

2 Últimamente, JORDÁN consideró en esta categoría las cinco inscripciones que UNTERMANN clasificó como: [K.9.2], [K.13.1], [K.13.2], [K.14.1] y [K.24.1]. Aunque hay que señalar que parece que JORDÁN incluyó este último texto mientras esta tésera de hospitalidad aún estaba en paradedro des-
} 
Revisión paleográfica de las inscripciones celtibéricas en signario paleohispánico...

total de objetos con inscripciones celtibéricas en signario paleohispánico es de poco más de un centenar (excluidas las leyendas monetales), resulta que el subconjunto de las alfabetizadas es realmente pequeño tanto en números absolutos como relativos ${ }^{3}$. Aunque su mera existencia es lo suficientemente interesante como para que hayamos decidido dedicarle un apartado especial a la hora de realizar su revisión paleográfica, como parte del trabajo que llevamos entre manos relativo al estudio arqueológico de las inscripciones celtibéricas.

\section{REVISIÓN PALEOGRÁFICA DE [K.9.2]}

La revisión del contexto arqueológico de las inscripciones celtibéricas ${ }^{4}$ conlleva la identificación y el estudio de los distintos alógrafos empleados en ellas, incluyendo el análisis de su distribución geográfica y temporal. Esta tarea ya nos permitió la detección de una interpunción en otra inscripción numantina que había pasado desapercibida hasta entonces, [K.9.1 $]^{5}$, y ahora nos permite exponer una sencilla explicación para algunos de los extraños alógrafos presentes en otra inscripción, [K.9.2], sin parangón en el corpus celtibérico. Esta inscripción fue pintada antes de su cocción y se encuentra en la parte superior del interior de un oi-

conocido y se creía que la lectura de su cara A era irorekiios monituukoos (:) nemaios. Esto es, antes de su reaparición y de la consiguiente revisión de la lectura de esta inscripción como kuirorekiios monituukoos (:) nemaios, perdiendo la sistemática aplicación de su alfabetización, ya que, quizá, esto le habría llevado a excluir [K.14.1] de este subconjunto, como hizo con el único caso conocido de aparente redundancia vocálica no sistemática, el de la tésera de hospitalidad que se ha venido leyendo como tertabiizum (:) Kaar, de la que también tratamos más adelante. Caso anómalo al que habría que añadir el de la palabra metuunos en la cara B del conocido como bronce Res, [K.0.14], que realizó BURILLO y que ha sido mantenida con reservas por JORDÁN, y que nosotros descartamos ya que proponemos leerla como mezunos y, por tanto, no relacionada con los textos cuya revisión es objeto del presente trabajo. Del mismo modo que también hay que señalar que JORDÁN corrigió la lectura del grafito numantino [K.9.5], que se venía leyendo como arebasikoo[ / s+[, como arebalbiiko+[ / s+[, con lo que introdujo una posible redundancia vocálica no sistemática. Sin embargo, aunque creemos que esta revisión paleográfica es correcta, también nos gustaría plantear la posibilidad de que no presentaría esta anomalía si su interpretación fuera arebalkeiko+[ / s+[, siguiendo la propuesta que hiciera VELAZA para interpretar el signo cuya morfología se parece gráficamente al del griego П como si fuera una variante de ke, en lugar de hacerlo serlo de bi y que últimamente cuestionaba pero que, de alguna manera, parece que PRÓSPER viene recuperando. UNTERMANN 1997, pp. 558-561, 665-666, 688-689, 683-688 y 712713, BURILLO 1989-1990, pp. 317-319 y 323, VELAZA 1999, pp. 675-676, JORDÁN 2005-2006, pp. 483-484, PRÓSPER 2007, pp. 51-54, JORDÁN 2007, pp. 131, 138-139, TORIJA y BAQUEDANO 2007, pp. 277-278, 319-320, 325-326 y 334-335, y PRÓSPER 2008, pp. 15-18.

3 Este número resulta aún más pequeño si, como señaló JORDÁN, se considera que en el medio centenar largo de monedas con leyenda celtibérica distintas o en las relacionadas con ellas no se da ningún caso de redundancia vocálica sistemática. A lo que podríamos añadir que tampoco se da redundancia parcial si excluimos el caso de la ceca unambaate. JORDÁN 2004, pp. 180-209.

4 En septiembre de 2007 OLCOZ obtuvo el Diploma en Estudios Avanzados en Arqueología (DEA) en Arqueología, en el departamento de Ciencias de la Antigüedad de la Universidad de Zaragoza, bajo la dirección del profesor Manuel Medrano con un trabajo titulado Arqueología de las Inscripciones Celtibéricas del que el presente trabajo puede considerarse una continuación.

${ }^{5}$ La identificación de la interpunción existente entre muko y kaiko, en [K.9.1], fue publicada por OL$\mathrm{COZ}$ en junio de 2007 y recogida en el trabajo presentado para la obtención del citado DEA. Posteriormente y ya en 2008 , SIMÓN ratificó esta relectura a la que este autor habría llegado por su cuenta. OLCOZ 2007, p. 47 y SIMÓN 2007, pp. 223-236. 
nochoe $^{6}$ hallado en el yacimiento arqueológico de Numancia (Garray, Soria) ${ }^{7}$, que fue datado entre la mitad o el tercer cuarto del siglo I a.C. y principios del siglo I d.C. ${ }^{8}$, siendo su lectura: Iuanikoo (:) koorinau.

No cabe duda de que la inscripción, realizada en la variante occidental del celtibérico, presenta repetición vocálica sistemática y a ello sólo se puede añadir que, según JORDÁN, en el caso de luanikoo y siguiendo su propuesta para la interpretación de la escritura dual en celtibérico, debería tratarse de la variante dual go, en vez de la de ko, que es la pronunciación que debería corresponder a esta palabra de acuerdo con la presencia de un alógrafo simple para este signo. Lo que le hizo considerar a esta inscripción como un documento de procedencia occidental con un sistema de escritura indefinible e inconsistente con su regulación de la escritura dual ${ }^{9}$.

El detallado estudio de los signos presentes en esta inscripción nos permitió detectar el error cometido por el escriba que la pintó en la parte superior del interior del oinochoe en el que se encuentra, así como la corrección que inmediatamente realizó tras percatarse de que se había olvidado de escribir la $\mathbf{r}$ de koorinau cuando sólo le faltaban los dos últimos signos de esta palabra, a y u, para completar la realización de la inscripción. Lo que explicaría el hecho de que volviera sobre sus pasos y escribiera la $\mathbf{r}$ omitida sobre la $\mathbf{i}$, haciendo que el alógrafo resultante de la $\mathbf{r}$ acabara presentando dos extraños trazos que no se dan en ningún otro caso para este signo, así como que reescribiera la i sobre la $\mathbf{n}$, escrita en la variante occidental del celtibérico, produciendo similares consecuencias para el alógrafo resultante de la i, así como que después siguiera escribiendo y completase la inscripción correctamente, añadiendo a continuación una nueva $\mathbf{n}$ y los signos a y $\mathbf{u}$ que le habían quedado pendientes de escribir al darse cuenta del fallo cometido (Fig. 1) ${ }^{10}$.

A pesar de este pequeño avance en el estudio paleográfico de esta inscripción, todavía no hay explicación para el extraño alógrafo empleado en el tercer signo de su primera palabra, que se viene interpretando como $\mathbf{a}^{11}$, y al que le so-

${ }^{6}$ BURILLO propuso que el texto fue pintado por el alfarero, reproduciendo el texto suministrado por quien realizó el encargo. BURILLO 1997, p. 233.

7 Aprovechamos la ocasión para dar las gracias por la inestimable colaboración y la amabilidad con la que nos atendieron, en junio de 2007, Elías Terés Navarro y Marian Arlegui Sánchez, director y conservadora del Museo Numantino (Soria), respectivamente. Así como por la cesión de la fotografía de la fig. 1, correspondiente a la pieza registrada con la signatura 11.874.

8 Aunque WATTENBERG fue de la opinión de que este oinochoe databa de la época entre la guerra sertoriana y las guerras cántabras, lo que se acerca más al período en el que está datado el otro oinochoe similar a éste, [K.5.1], que fue hallado en el yacimiento arqueológico de La Caridad (Caminreal, Teruel, Aragón), esto es, entre finales del siglo II y las primeras décadas del I a.C. WATTENBERG 1963, pp. 115 y 208, ARLEGUI 1992, p. 477 y VICENTE, PUNTER, ESCRICHE y HERCE, 1993, pp. 759-760.

9 JORDÁN 2007, p. 113.

10 El paso del tiempo y, quizá, el proceso de restauración del oinochoe, han hecho que se pierda parte de la primera o y, sobre todo, de la interpunción que separa las dos palabras que forman la inscripción, como se puede comprobar si se compara esta figura con la fotografía que publicó UNTERMANN hace más de una década. UNTERMANN 1997, p. 665.

11 JORDÁN recordó que FATÁS había preferido interpretarlo como tu, lectura que también daba al penúltimo signo de la inscripción, por razones paleográficas y a pesar de presentar un alógrafo diferente. Lectura que últimamente no se tiene en cuenta y que, además, sería inconsistente con la redundancia vocálica sistemática de esta inscripción. FATÁS 1985, p. 558, JORDÁN 2004, p. 211 y JORDÁN 2007, p. 113. 


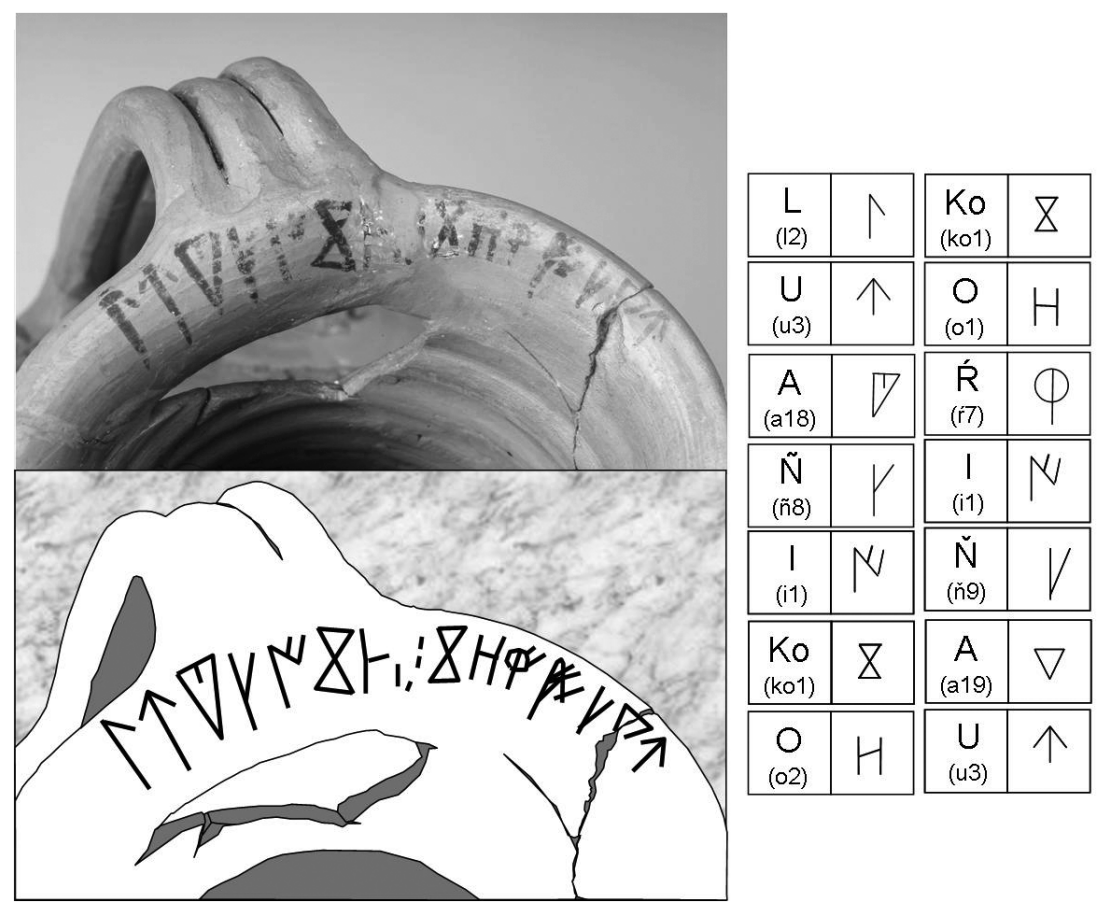

Fig. 1.

braría la pequeña línea vertical que le hace único y cuyo posible significado aún se nos escapa ${ }^{12}$.

No obstante, cabe señalar la trascendencia que podría tener a la hora de valorar el uso de inscripciones en objetos de destacado valor o, al menos, relacionados con su particular uso en determinados rituales ${ }^{13}$, e incluso en general pues llama la atención que si tan extraordinaria era la presencia de este tipo de inscripciones, se admitiera la recepción por el destinatario del objeto adquirido al alfarero a pesar de las evidentes muestras de la corrección de los errores tipográficos que se habían producido en su manufactura y que, a pesar de ello, se le diera el uso al que estaba destinado. Quizá haya que considerar que entonces, como ahora, se daban errores en la escritura incluso donde menos deberían verse y que su uso entre los celtíberos no siempre era tan excepcional como podría pensarse al haberse hallado esta muestra de sus errores y correcciones.

${ }_{12}$ Cabría plantear la posible ligadura bia que llevaría a la lectura de lubianikoo, en caso de que pudiera tratarse de un nuevo hápax celtibérico.

13 BURILLO relacionó esta inscripción numantina, [K.9.2], y la hallada en un objeto similar en el citado yacimiento arqueológico de La Caridad, [K.5.1] como base para explicar la existencia de vasijas excepcionales para fines excepcionales. BURILLO 1997, pp. 229-230. 


\section{REVISIÓN PALEOGRÁFICA DE [K.13.1]}

Entre las lápidas funerarias celtibéricas procedentes del yacimiento arqueológico de Clunia (Peñalba de Castro, Burgos, Castilla y León) se encuentra una, [K.13.1], que data de mediados del siglo I a.C. ${ }^{14}$ y que, bajo la figura de un jinete ecuestre y entre las patas del caballo, contiene una inscripción, grabada en la variante occidental del celtibérico, cuya lectura es kaabaarinos, (Fig. 2 ${ }^{15}$. Descripción paleográfica a la que sólo podemos añadir que JORDÁN clasificó este documento como de procedencia occidental, con un sistema de escritura característico de esta región celtibérica pero inconsistente con la regulación de la escritura dual ${ }^{16}$.
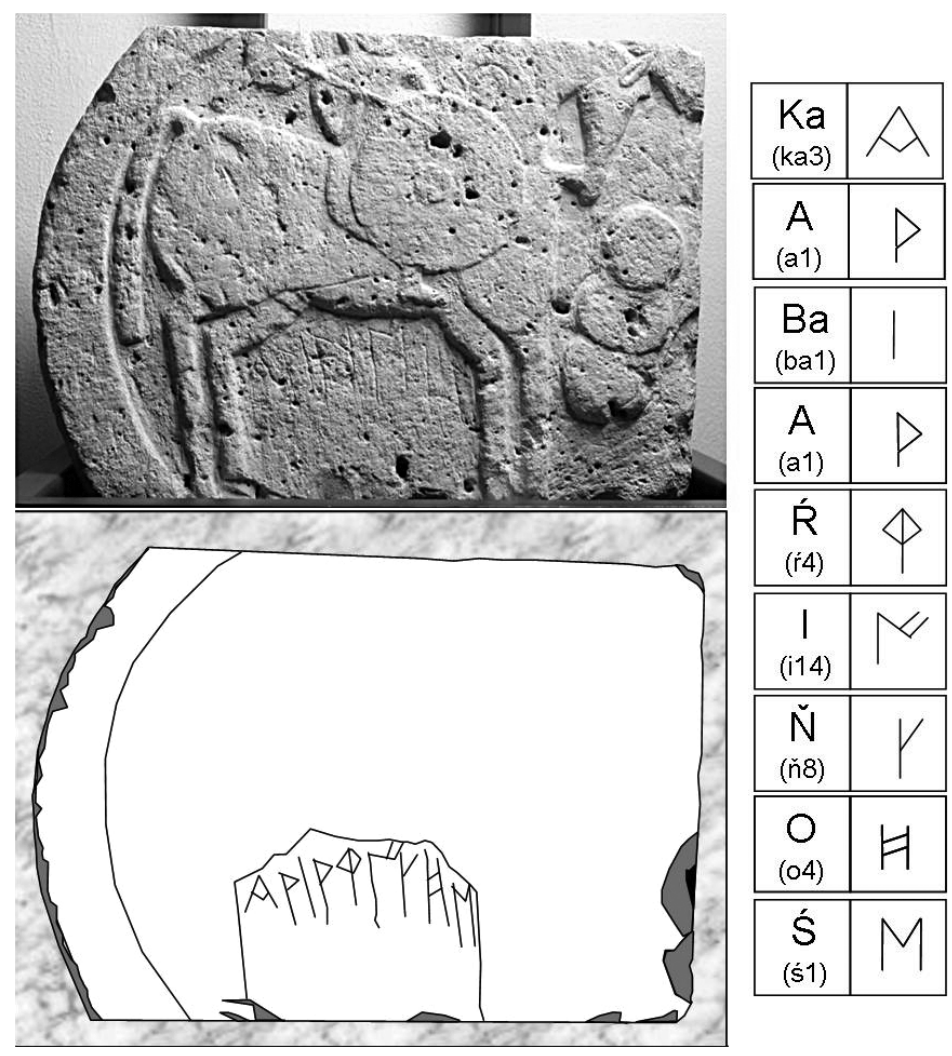

Fig. 2.

14 PALOL y VILELLA 1987, pp. 17-18.

15 Fotografía adquirida en el Archivo Fotográfico del Museo Arqueológico Nacional, siendo la referencia de la estela MAN 1977/24/2.

${ }^{16}$ Incoherencia que JORDÁN expuso que desaparecería si existiera una relación con el genónimo CAMBARICVM. JORDÁN 2007, pp. 113-114. 


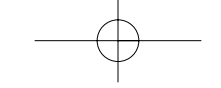

Revisión paleográfica de las inscripciones celtibéricas en signario paleohispánico...

\section{REVISIÓN PALEOGRÁFICA DE [K.13.2]}

También fue hallada en Clunia otra lápida funeraria, de época similar a la de la anterior y también realizada en la variante occidental del celtibérico, que contenía una inscripción grabada en su cara anterior, encima de la representación de un guerrero de infantería dispuesto a enfrentarse con un toro, [K.13.2], cuya lectura era mukuukaaiau y que, aunque suele citarse como desaparecida, parece que ya había sido destruida cuando trataron de localizarla a principios del siglo $\mathrm{XIX}^{17}$. Por lo que sólo se conservan el dibujo publicado por LOPERRÁEZ, en 1778, así como la variante de éste que también publicó ERRO poco más de un cuarto de siglo después, destacando la existencia de una punción en el interior del tercer signo que, habitualmente, se suele pasar por alto ${ }^{18}$ (Fig. 3). Este detalle acerca del signo ku junto con el complejo alógrafo empleado para representar el de ka permitirían pronunciarse sobre su carácter dual e incluir a esta inscripción entre los documentos clasificados por JORDÁN como originarios de la zona occidental de Celtiberia y con escritura coherente con su descripción del sistema dual, en lugar de considerarla como originaria de la zona occidental pero con sistema de escritura indefinible ${ }^{19}$.

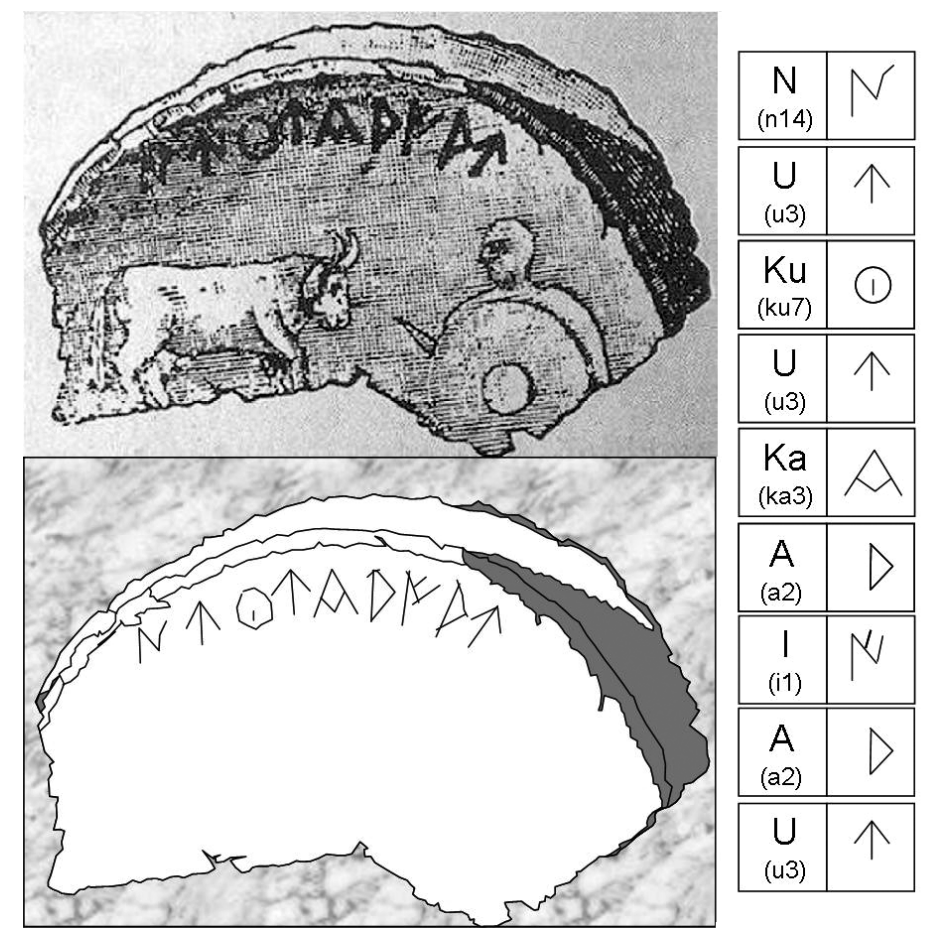

Fig. 3.

17 ERRO 1806, pp. 152-158 y 161.

18 LOPERRÁEZ, pp. 327-328 y ERRO 1806, pp. 152-158 y 161.

19 JORDÁN 2007, pp. 119 y 132. 


\section{REVISIÓN PALEOGRÁFICA DE [K.14.1]}

La redundancia vocálica también se da entre las téseras de hospitalidad, concretamente, en dos o incluso tres de ellas, todas zoomorfas. La primera tiene forma de toro, procede del entorno de la ciudad romana de Segisamo (Sasamón, Burgos) y también está escrita en la variante occidental del celtibérico. Aunque, tras haber sido recientemente recuperada, la lectura de las inscripciones grabadas en sus dos caras, [K.14.1], es kuirorekiios monituukoos (:) nemaios y aletuures, respectivamente ${ }^{20}$, (Fig. 4$)^{21}$. Con lo que la redundancia vocálica habría dejado de ser sistemática en la cara $A^{22}$, al no tener una $\mathbf{u}$ tras el signo de la ku que ya estaba presente en el calco publicado inicialmente por GÓMEZ ${ }^{23}$. A no ser que el olvido de esta u sea la prueba del error cometido por el escriba que realizó el grabado de esta tésera de hospitalidad y que, a diferencia del caso numantino, [K.9.2], no fue corregido antes de la entrega del objeto a su destinatario.

JORDÁN consideró este documento como de procedencia occidental, seguramente, basándose sólo en el estilo de su escritura y en el lugar en que fue hallado pero sin tener en cuenta que fue encontrado fuera del territorio celtibérico, concretamente, al noroeste de su zona occidental y que esta anomalía podría explicarse con la propuesta que hicimos acerca de su posible vinculación con las relaciones entre la población indígena y las legiones romanas, en el contexto histórico de las guerras cántabras, por tanto, datándola en el primer cuarto del siglo I a.C. ${ }^{24}$. Al margen de esto, JORDÁN también lo calificó entre los documentos que consideró como indefinibles con respecto al sistema dual de escritura aunque la abundancia de trazos que presenta la mayoría de sus signos le podría hacer decantarse por considerarlo en contra de su carácter dual ${ }^{25}$. Impresión que se vería

20 Las editoras de esta tésera de hospitalidad fueron de la opinión de que su forma correspondía más a una ternera que a un toro y, además, identificaron la interpunción formada por tres pequeñas líneas que separa las dos últimas palabras de la cara A. Si bien no parece correcto considerar que la marca incisa, hecha con un troquel con dos círculos concéntricos alrededor de un tercer círculo situado en el centro de la cara A, fuera realizado con posterioridad a la inscripción, como expusieron TORIJA y BAQUEDANO, ya que los trazos de ésta corta los bordes de dichos círculos aunque se interrumpen en su interior. TORIJA y BAQUEDANO 2007, pp. 277-278, 319-320, 325-326 y 334-335.

${ }_{21}$ Fotografías de ambas caras de esta tésera de hospitalidad que también fueron adquiridas en el Archivo Fotográfico del Museo Arqueológico Nacional, siendo sus referencias MANF2007_55_1R y MANF2007_55_SEQ_00.

${ }^{22}$ La confirmación de este posible caso de redundancia vocálica no sistemática permitiría recuperar la lectura de [K.9.5] como arebalbiiko+[ / s+[, sin necesidad de que, por este motivo, se tuviera que recurrir a su posible lectura como arebalkeiko+[ / $\mathbf{s + [}$.

${ }^{23}$ GÓMEZ incluyó un signo ku, redondo y con un punto central, al comienzo de esta inscripción. Creemos que este signo ku parece tener en su interior los vestigios de lo que pudo ser una pequeña línea que TORIJA y BAQUEDANO no mencionaron y como no hemos podido comprobarlo completamente al no poder acceder a la pieza en persona, por hallarse embalada debido a las obras en curso en el Museo Arqueológico Nacional, y sólo haber podido revisar sus fotografías, nos hemos decido por mantener la lectura de sus últimos editores para identificar su alógrafo correspondiente. GÓMEZ 1949, p. 205.

${ }^{24}$ Entonces no pudimos estudiar esta tésera pues estaba en proceso de ser transferida al Museo Arqueológico Nacional y tuvimos que conformarnos con citarla basándonos únicamente en el calco publicado por GÓMEZ hacía casi medio siglo. GÓMEZ 1949, p. 205 y OLCOZ y MEDRANO 2005-2007(b), pp. 210-211.

25 JORDÁN 2007, p. 114. 


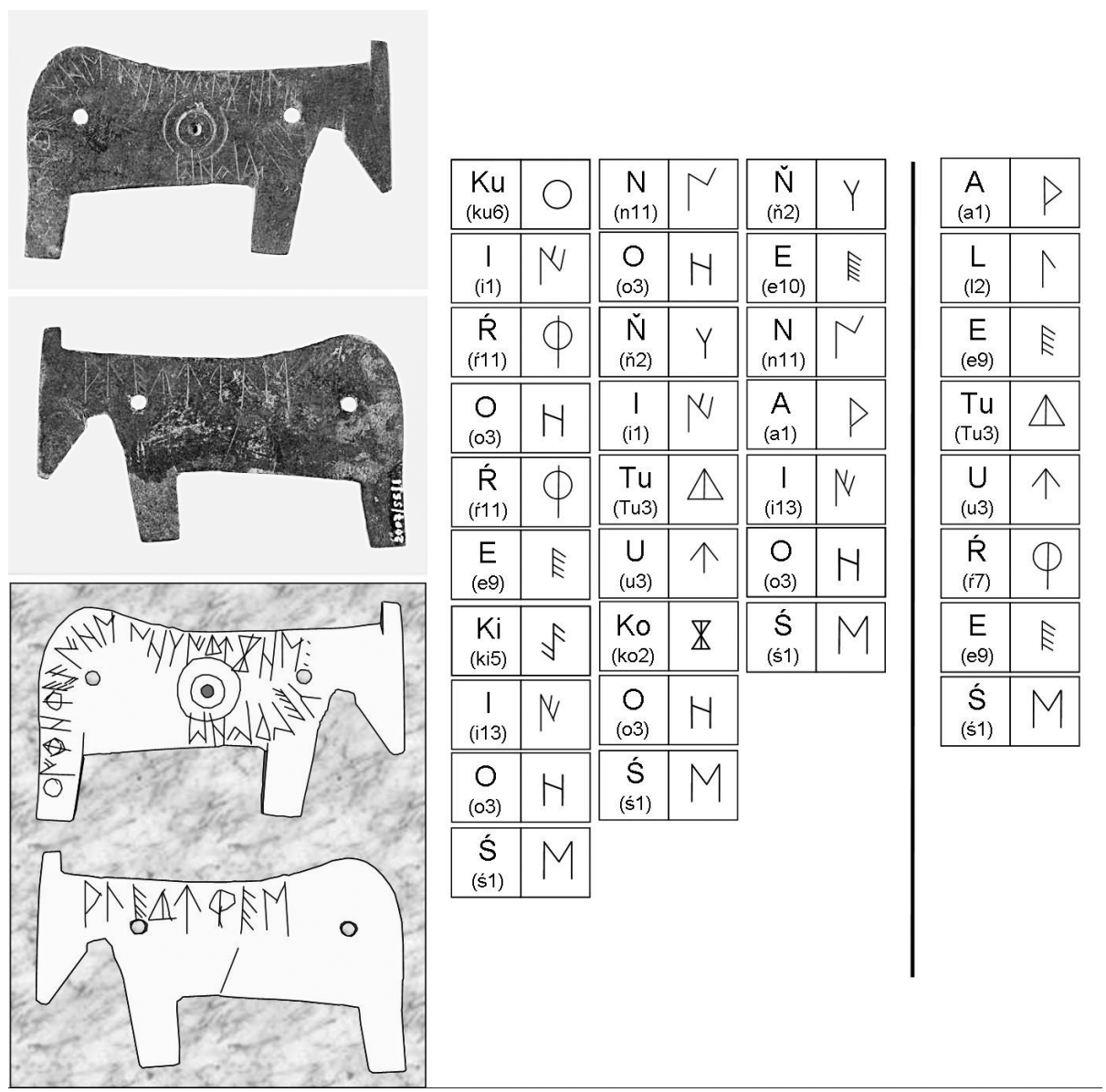

Fig. 4.

reforzada por la posibilidad de que el signo ku también tenga en su interior la citada raya.

Finalmente, añadir que también nos cabe la duda de si existen algunos vestigios de otra posible interpunción entre las dos primeras palabras de la cara $A$, que darían como posible lectura kuirorekiios (:) monituukoos (:) nemaios y aletuures, respectivamente. Duda que esperamos resolver cuando finalmente tengamos acceso a la inscripción.

\section{REVISIÓN PALEOGRÁFICA DE [K.24.1]}

En una tésera de hospitalidad pisciforme, procedente del yacimiento arqueológico de La Mesa (Belorado, Burgos), cercano al de la ciudad de Segisamonculum 


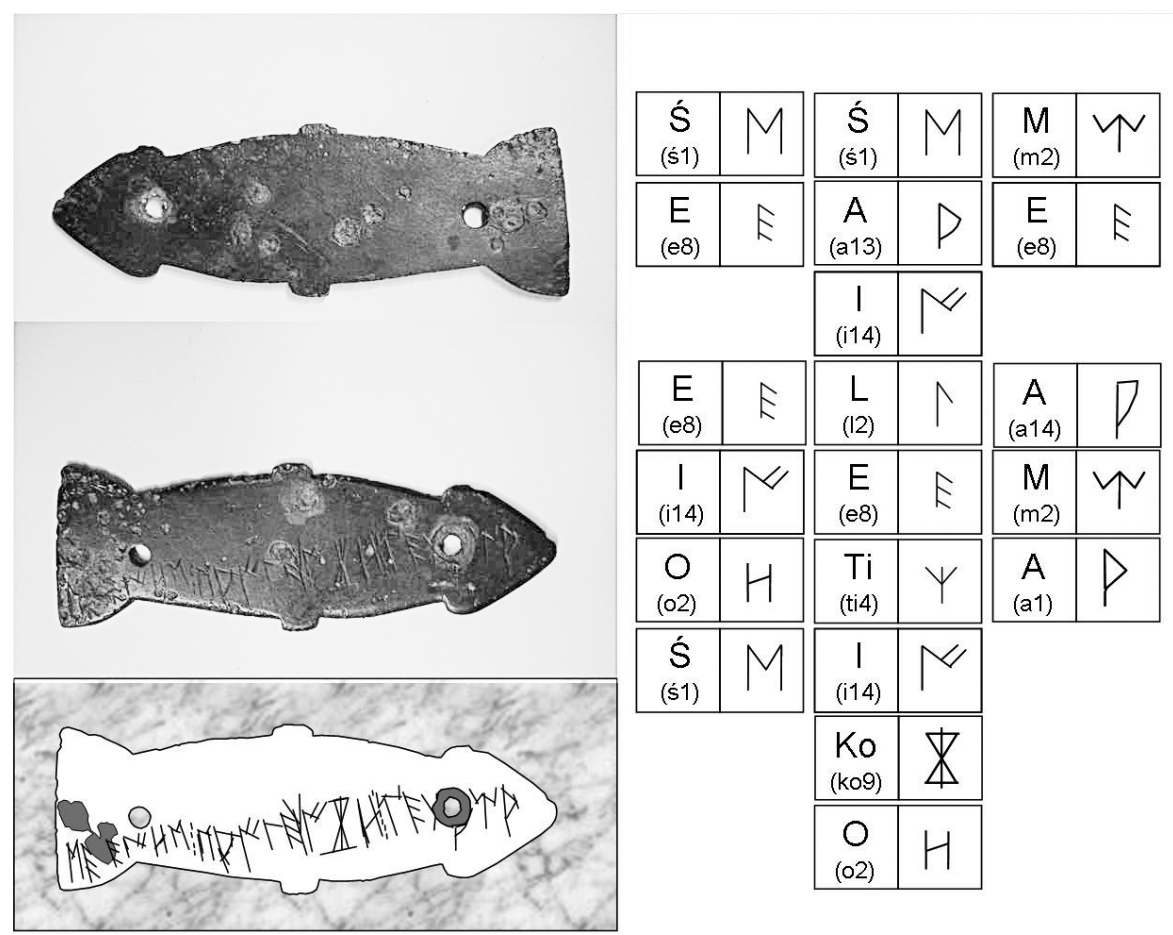

Fig. 5.

(Cerezo del río Tirón, Burgos), también hay una inscripción grabada sobre el bronce en la que se observa la redundancia vocálica y cuya lectura es sekeeios (:) sailetiikoo (:) metaama ${ }^{26}$, (Fig. 5).

Esta tésera de hospitalidad fue escrita en la variante oriental del celtibérico pero fue hallada muy lejos de su ámbito natural ya que la encontraron en un yacimiento romano ubicado fuera del territorio celtibérico, también al noroeste de su zona occidental e igualmente la vinculamos con el contexto histórico de las guerras cántabras, por tanto, datándola del primer cuarto del siglo I a.C. ${ }^{27}$. Posible relación que JORDÁN no tuvo en cuenta y que quizá por ello lo clasificó sólo como un documento discordante, procedente de la zona occidental de Celtiberia y coherente con el sistema dual de escritura ${ }^{28}$.

${ }^{26}$ En su momento creímos que había vestigios del signo ke como para aventurar su alógrafo y que también los había para decantarse por una determinada variante del signo ta. Tras la nueva revisión de la inscripción ya no estamos tan seguros de ello y por eso los hemos reconsiderado como dudosos y no hemos podido determinar su alógrafo correspondiente. OLCOZ y MEDRANO 2005-2007(b), pp. 212-213.

${ }^{27}$ En Cerezo del río Tirón se localiza la ciudad romana de Segisamonculum donde también se considera la posibilidad de que en ella pudo haber estado la ceca de sekisamos, por la que pasaba la calzada que, procedente del valle del Ebro, se internaba por la meseta y comunicaba esta ciudad autrigona con las vecinas Briviesca y Segisamo de los turmogos, por medio de la vía De Hispania in Aquitaniam. Ab Asturica Burdigalam. OLCOZ y MEDRANO 2005-2007(b), pp. 212-213.

28 JORDÁN 2007, pp. 119 y 139. 


\section{REVISIÓN PALEOGRÁFICA DE [PD-1]}

Además de los cinco documentos ya revisados e identificados previamente por JORDÁN como casos de uso del sistema de escritura redundante, existe uno más que también contiene una inscripción grabada en la variante oriental del celtibérico y que quizá podría añadirse a este pequeño conjunto de documentos en signario paleohispánico alfabetizado. Se trata de la tésera de hospitalidad procedente del lugar en el que hubo un campamento sertoriano, en el invierno del 77 al 76 a.C., en el límite entre las localidades navarras de Fitero y Cintruénigo ${ }^{29}$ y cuya inscripción, grabada en la variante oriental del celtibérico, DÍAZ y JORDÁN leyeron como tertabiizum (:) kaar ${ }^{30}$.

Una detallada revisión de las fotografías que nos facilitó REMíREZ ${ }^{31}$ nos ha permitido explicar las posibles circunstancias en las que pudo producirse la corrección que condujo a la redundancia vocálica de kaar, tras completar la realización de la inscripción y que, al repasar el trabajo, decidiera escribir una a sobre la última $\mathbf{r}$, quedándole así ésta algo desproporcionada para poder cubrir y enmendar el error del que aún quedan unos vestigios, y después añadió una nueva $r$ al final de la inscripción, al estilo de la corrección que realizó el pintor de la inscripción numantina [K.9.2], porque en ambos casos aún les quedaba espacio libre a la derecha de la inscripción, (Figs. 6 y 7).

Dado que en este documento celtibérico, como en el caso de [K.14.1] y de otros ya señalados en el presente trabajo ${ }^{32}$, la aplicación de la alfabetización del signario paleohispánico tampoco fue sistemática y que también muestra vestigios de la corrección del error cometido por el escriba que grabó la inscripción, cobra mayor fuerza la posibilidad de que se diese una escritura con redundancia vocálica parcial o asistemática quizá concurrente o previa a la etapa de su aplicación sistemática y, en cualquier caso, como paso previo al de la adopción del alfabeto latino. El hecho de que, además, en ambos casos, se produjeran y enmendaran errores tipográficos podría ser también un testimonio de los efectos producidos por dichos cambios en el sistema de escritura celtibérica ya que pudo provocarlos con mayor asiduidad que durante el uso de un sistema de escritura más asentado o en una etapa menos variable de su evolución.

29 OLCOZ y MEDRANO 2006, p. 59.

30 MEDRANO y DÍAZ, p. 42 y DÍAZ y JORDÁN 2006, pp. 262-265.

31 Poco después del hallazgo clandestino de esta tésera de hospitalidad y poco antes de que pasase a estar en paradero desconocido, [PD-1], el arqueólogo y amigo Salvador Remírez Vallejo tuvo la ocasión de fotografiarla en Cintruénigo, en abril de 2003. Aprovechamos la ocasión para agradecerle la cesión de las fotografías digitales que nos facilitó para su estudio. Así como para destacar que en la fotografía de la cara que tiene la inscripción todavía se aprecia cerrado por el óxido el agujero que, después, se ve con claridad que traspasaba la pieza en la fotografía de su otra cara.

${ }_{32}$ Casos a los que cabría añadir el de la tésera de hospitalidad escrita en alfabeto latino que REMESAL leyó como CAAR (:) ICVRBICA / SALVANTICA / QVE, que tiene forma de cabeza de lobo y que fue hallada muy lejos del territorio celtibérico considerado como tal habitualmente: el yacimiento arqueológico de la Mesa del Almendro, en Lora del Río (Sevilla, Andalucía). REMESAL 1999, pp. 595-603. 


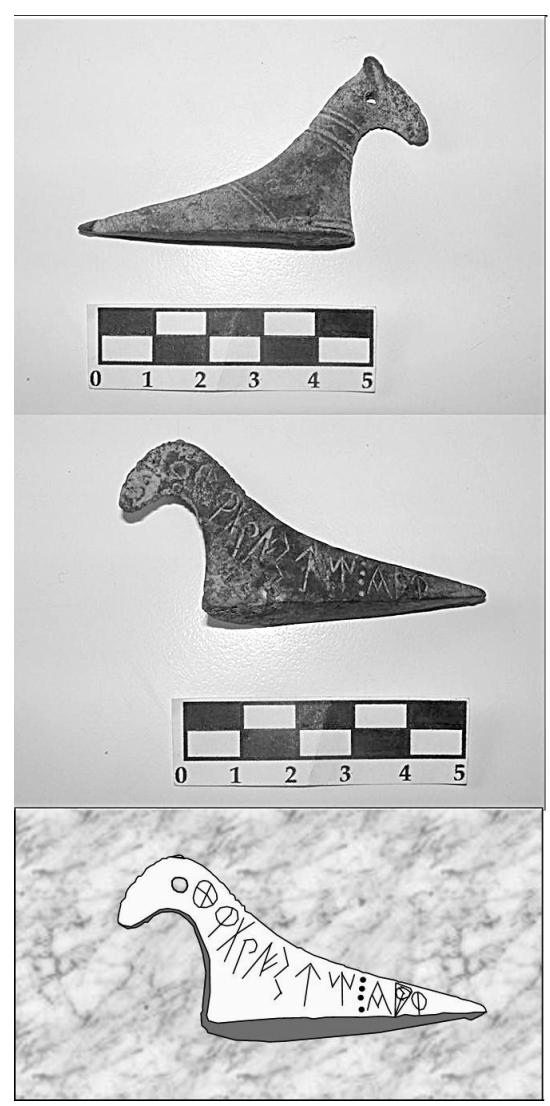

\begin{tabular}{|c|c|c|c|}
\hline $\begin{array}{c}\mathrm{Te} \\
\text { (te14) } \\
\end{array}$ & $\oplus$ & $\begin{array}{c}\mathrm{Ka} \\
\text { (ka3) } \\
\end{array}$ & $\Delta$ \\
\hline $\begin{array}{c}R \\
(\dot{R} 13) \\
\end{array}$ & (1) & $\underset{(\mathrm{a} 20)}{\mathrm{A}}$ & $\nabla$ \\
\hline $\begin{array}{c}\mathrm{Ta} \\
\text { (ta1) }\end{array}$ & $x$ & $\begin{array}{l}\dot{R} \\
\text { (i7) }\end{array}$ & $\Phi$ \\
\hline$\underset{(\mathrm{bi} 3)}{\mathrm{Bi}}$ & $P$ & & \\
\hline $\begin{array}{c}1 \\
(113)\end{array}$ & N & & \\
\hline $\begin{array}{c}\mathrm{S} \\
(\mathbf{s} 18) \\
\end{array}$ & \} & & \\
\hline$\underset{(\mathrm{U} 1)}{U}$ & $\hat{\imath}$ & & \\
\hline$\underset{(m 1)}{M}$ & $\checkmark$ & & \\
\hline
\end{tabular}

Fig. 6.

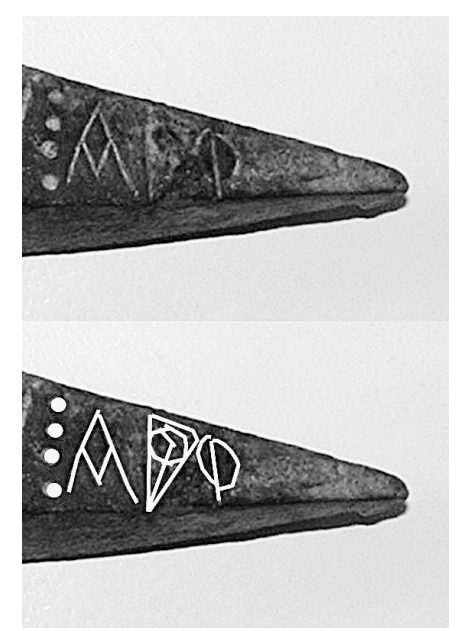

Fig. 7. 


\section{DISTRIBUCIÓN GEOGRÁFICA Y CRONOLÓGICA DE ESTOS HALLAZGOS}

JORDÁN destacó el hecho que la mayoría de las inscripciones celtibéricas escritas en signario paleohispánico alfabetizado o sistema de escritura redundante fueron halladas en la zona occidental de Celtiberia, asumiendo además que [K.9.2] (Numancia), [K.13.1] y [K.13.2] (Clunia) fueron realizadas en los mismos lugares en los que fueron halladas. A lo que añadió que también fueron halladas en la zona occidental las téseras de hospitalidad [K.14.1] (Sasamón) y [K.24.1] (Belorado) sin tener en cuenta que sería más correcto decir que fueron halladas al noroeste de Celtiberia y fuera de su territorio, pudiendo explicarse su hallazgo allí por medio de la posible relación existente entre ambos objetos y el contexto histórico-geográfico de las guerras cántabras. De este modo, además, no habría discordancia en el hecho de que la segunda de ellas estuviera escrita en la variante oriental y fuera hallada tan lejos de su territorio pues no lo sería tampoco en el de Celtiberia occidental, como expuso JORDÁN ${ }^{33}$, sino, siendo más precisos, fuera de éste.

Por otra parte, teniendo en cuenta que tanto estos dos documentos como el hallado en Cintruénigo, [PD-1], en el contexto histórico-arqueológico del citado campamento sertoriano, son téseras de hospitalidad y que bien podría vincularse el lugar de su hallazgo con las itinerantes relaciones entre los indígenas locales y los que acompañaban a las tropas romanas que participaron en ambas campañas del siglo I a.C., el hecho de que dos de estas inscripciones paleohispánicas alfabetizadas fueran escritas en la variante oriental del celtibérico dejaría de ser un elemento discordante si se asocia su alfabetización a la relación de quienes los usaron con las tropas romanas y, por tanto, a la influencia de la cultura latina de éstas $\mathrm{o}$, si se prefiere, del lugar en el que estas operaban y que sería el del lugar en el que se hallaron, (Fig. 8), en vez de explicarla considerando sólo la discordancia existente entre el lugar en el que fueron hallados y el que debieron ser realizados estos documentos de acuerdo con su clasificación en la variante oriental u occidental del sistema de escritura celtibérico.

No obstante, el hecho de que se conozcan inscripciones celtibéricas realizadas en la variante occidental sin que presenten redundancia vocálica, claramente procedentes de esta región y también datadas en el siglo I a.C., como por ejemplo las lápidas sorianas de Trébago, [K.10.1], y Langa de Duero, [K.12.1] ${ }^{34}$, parece debilitar el argumento expuesto por JORDÁN para explicar con un criterio principalmente geográfico, la existencia de diferentes procesos de evolución en la escritura celtibérica, según se trate de su variante oriental u occidental. Más aún si se tiene en cuenta que perduran algunas inscripciones celtibéricas en signario paleohispánico hasta el siglo I o incluso el II d.C. ${ }^{35}$ y también que la distribución de ins-

\footnotetext{
33 JORDÁN 2007, p. 139.

${ }^{34}$ GONZÁLEZ dató la estela de Trébago en el siglo I a.C. y JIMENO hizo lo mismo con la de Langa de Duero. GONZÁLEZ 1986, p. 55, y JIMENO 2005, p. 558.

${ }_{35}$ JORDÁN expuso que la cronología estos testimonios [escritos en celtibérico] abarca los siglos II y I a.C. Sin embargo, además de los grabados del santuario rupestre de la montaña de Peñalba (Villastar,
} 

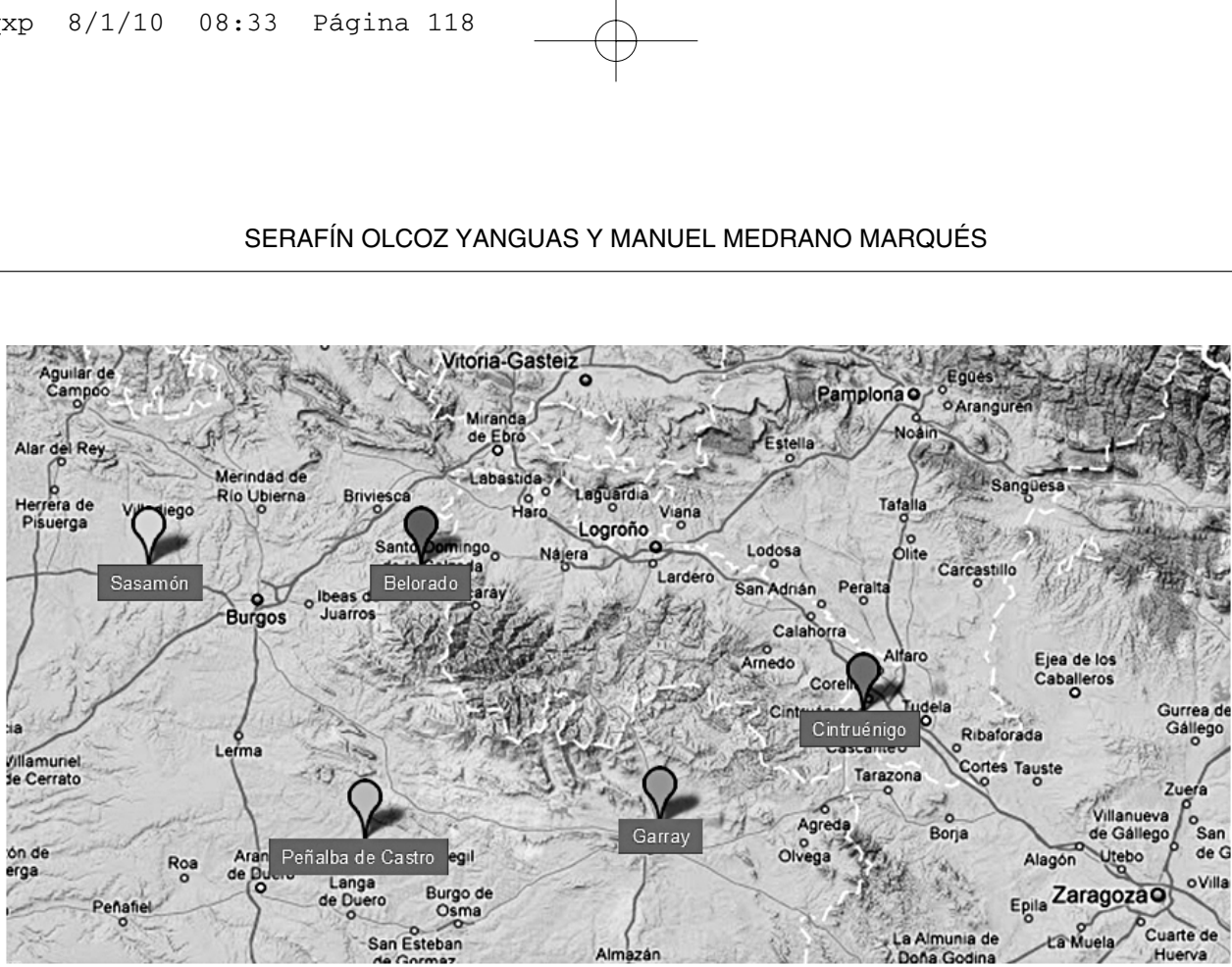

Fig. 8.

cripciones celtibéricas escritas en alfabeto latino cubre tanto ambas zonas de Celtiberia como lugares fuera de estos territorios y que es en estos últimos, datados todos ellos alrededor del cambio de Era, en los que mayor número de objetos con este tipo de inscripciones se han hallado. Por lo que creemos que es necesario avanzar en el conocimiento arqueológico e histórico de los lugares en los que fueron encontrados y de los que procedían los objetos con inscripciones celtibéricas para poder conocer mejor el proceso de evolución de su sistema de escritura, incluyendo el de sus variantes regionales.

Finalmente, el hecho de que los seis documentos celtibéricos escritos en signario paleohispánico alfabetizado, parcial o totalmente, daten del siglo I a.C. o que

Teruel), [K.3.1-3], datados alrededor del cambio de Era, ya se conocían dos testimonios que llegaban hasta el siglo II d.C.: un grafito incompleto sobre un fragmento de cerámica altoimperial romana, hallado en las excavaciones arqueológicas realizadas en 1962, en la scaena del teatro romano de Segobriga (Saelices, Cuenca), y datado en la segunda mitad del siglo I d.C. por ALMAGRO y otro grafito incompleto sobre otro fragmento de cerámica indígena hallado en las excavaciones realizadas en 1978, en el relleno del acueducto de la ciudad de Termes (Montejo de Tiermes, Soria) y datado por ARGENTE et alii entre la mitad del siglo I y el II d.C. Además y aunque descartamos varios grafitos supuestamente celtibéricos y posteriores al cambio de Era en la revisión de inscripciones paleohispánicas halladas en La Rioja que realizamos OLCOZ, LUJÁN y MEDRANO —-por tratarse de inscripciones latinas, en el caso de algunas de las propuestas como posibles inscripciones celtibéricas por TIRADO, o de mera decoración y no de inscripciones, ni siquiera simbólicas, en el de las que hizo BALLESTER-, a los que habría que añadir el grafito hallado en un fragmento de cerámica, datado en el siglo I d.C., junto al puente del ferrocarril que cruza el río Manzanares en Villaverde Bajo (Madrid) durante las excavaciones de 1928, que había sido recogido por BLASCO y ALONSO como paleohispánico y que resultó ser latino, también hay que añadir como correcto testimonio de esta época la inscripción hallada en el verano de 2005, en Cascante (Navarra), que está datada hacia la primera mitad del siglo I d.C. CABRÉ 1910, pp. 256-258, ARGENTE et alii 1980, pp. 218, 223 y 231, BLASCO y ALONSO 1983, pp. 129-130, ALMAGRO 1984, p. 21, UNTERMANN 1997, pp. 618-627, TIRADO 2000, pp. 55, 63-64, 75, 78-79 y 115-116, BALLESTER 2001, pp. 257 y 259, JORDÁN 2004, p. 34, ANDREU 2006, p. 65, GÓMARA 2006, pp. 357 y 359, GÓMARA 2007, p. 266 y OLCOZ, LUJÁN y MEDRANO 2007, pp. 115-134. 
Revisión paleográfica de las inscripciones celtibéricas en signario paleohispánico...

incluso alguno de ellos pueda ser de principios del siglo I d.C. permite acotar el período temporal en el que pudo producirse la evolución de este sistema de escritura o, en cualquier caso, ayuda a situar el contexto histórico en el que se produjo este fenómeno en las distintas regiones. Sin olvidar que su número es muy pequeño y que, en cualquier caso, es significativa la presencia en ellos de errores cometidos por sus escribas, fueran corregidos o no.

\section{CONCLUSIONES}

Las inscripciones celtibéricas elaboradas en signario paleohispánico alfabetizado fueron realizadas en buena parte de los tipos de soporte y técnicas de escritura: una de ellas fue pintada sobre cerámica, previamente a su cocción, mientras que el resto fueron grabadas en estelas funerarias de piedra y en téseras de hospitalidad zoomorfas y de bronce. Quizá pueda ser importante destacar que este tipo de escritura no aparece en soporte monetal ni rupestre y que tampoco se encuentra en los largos textos sobre placas de metálicas.

Respecto a la autoría de este tipo de inscripciones, al menos en el caso de las estelas funerarias, se puede concluir que fueron hechas por encargo y que, por tanto, su autor fue distinto que su destinatario. Algo que también podría haber ocurrido en el caso de la cerámica y de las téseras de hospitalidad y como, además, ninguno de estos textos hace referencia a su posible propietario, como sería el caso de algunos de los nombres grabados o pintados tras su cocción en piezas de cerámica de mesa, no sería demasiado aventurado proponer que es muy probable que todos ellos tengan en común el que fueron hechos por encargo o sea que su autor fue distinto de su destinatario.

Poco más se puede decir que afecte al conjunto de los seis documentos estudiados, salvo recordar que el lugar de su hallazgo y el estilo de la variante regional de su escritura no parecen ser un criterio suficiente como para circunscribir este tipo de escritura alfabetizada al ámbito occidental celtibérico, donde se hallaron todos ellos, si incluimos en él territorios externos pero ubicados también al noroeste de Celtiberia. Aunque no hay duda de la influencia que en este tipo de escritura tuvo la presencia romana y la consecuente aculturación latina, especialmente en el contexto de los principales conflictos bélicos que asolaron la península Ibérica en el siglo I a.C. Por lo que éste contexto, incluyendo las relaciones comerciales y logísticas, además de las propiamente bélicas, entre los indígenas y las tropas romanas, puede ofrecer información complementaria a la lingüística y geográfica para poder entender mejor a qué se debió esta alfabetización del signario paleohispánico en celtibérico y qué papel desempeñó en esta forma de escritura en las diversas etapas que pudieron componer el proceso de adopción de la lengua latina en detrimento de la celtibérica.

Además, como hemos detectado errores corregidos en dos de los seis documentos revisados y esto supone un tercio del escaso número de los conocidos en los que parece que se empleó el signario paleohispánico alfabetizado, quizá tam- 
bién cabría considerar la posibilidad de que estos errores sean un testimonio de los cambios que se originaron en el citado proceso de alfabetización y a los que tuvieron que adaptarse los escribas que realizaban documentos por encargo empleando dicho signario o el alfabeto latino, indistintamente, según el cliente o la ocasión.

La revisión paleográfica de estos documentos ha permitido despejar algunas dudas acerca de los alógrafos empleados en ellos, así como mejorar la lectura de otros, tras encontrar correcciones. Lo que, indirectamente, nos ha ayudado a ver una faceta más humana en quienes realizaron estas inscripciones pues nos ha mostrado que también se equivocaban y cómo enmendaron alguno de sus errores, dejando quizá otros sin corregir. Mientras que la falta de explicación o de información acerca de otros alógrafos nos ha impedido avanzar más en el conocimiento de sus correspondientes inscripciones.

Finalmente, conviene insistir en el hecho de que el número de inscripciones celtibéricas realizadas en signario paleohispánico alfabetizado, sistemática y asistemáticamente, es tan pequeño que es muy difícil poder extraer ninguna conclusión definitiva acerca de su incidencia con respecto a la también escasa muestra total de inscripciones celtibéricas y, por tanto, de su valor como referente de la influencia del proceso de latinización con el que se viene relacionando.

\section{BIBLIOGRAFÍA}

ALMAGRO BASCH, Martín (1984), Segobriga II: Inscripciones Ibéricas, Latinas Paganas y Latinas Cristianas, en Excavaciones Arqueológicas en España, n. 127, Madrid, p. 443.

ANDREU PINTADO, Javier (2006), Aspectos del Poblamiento en la Comarca de Tudela de Navarra en Época Romana, en Cuadernos del Marqués de san Adrián, Tudela, pp. 59138.

ARGENTE OLIVER, José Luis; DE LA CASA MARTÍNEZ, Carlos; DÍAZ DÍAZ, Adelia; IZQUIERDO BÉRTIZ, José M. ${ }^{\text {; }}$ JIMENO MARTÍNEZ, A.; REVILLA ANDÍA, M. ${ }^{a}$ Luisa, (1980), Tiermes I (Campañas 1975-1978), en Excavaciones Arqueológicas en España, n. 111, Madrid, pp. 218, 223 y 231.

ARLEGUI SÁNCHEZ, Marian (1992), Las Cerámicas de Numancia con Letrero lbérico, en II Symposium de Arqueología Soriana. Homenaje a D. Teógenes Ortego y Frías. (Volumen I), Soria, pp. 473-494.

BALLESTER GÓMEZ, Xaverio, (2001), Nuevos Letreros Celtibéricos Procedentes de Calahorra, en Kalakorikos, n. 6, Calahorra, pp. 255-261.

BLASCO BOSQUED, M. ${ }^{a}$ Concepción; ALONSO SÁNCHEZ, M. Ángeles, (1983), Aproximación al Estudio de la Edad de Hierro en la Provincia de Madrid, en Homenaje al Prof. Martín Almagro Basch, Vol. III, Madrid, pp. 119-134.

BURILLO MOZOTA, Francisco (1997), Textos, Cerámicas y Ritual Celtibérico, en Kalathos, n. 9-10, Teruel, pp. 313-331.

- (1989-1990), Un Nuevo Texto Celtibérico: El Bronce «Res̀, en Kalathos, n. 16, Teruel, pp. 223-242.

CABRÉ AGUILÓ, Juan (1910), La Montaña Escrita de Peñalba, en Boletín de la Real Academia de la Historia, n. 56, Madrid, pp. 223-242. 
Revisión paleográfica de las inscripciones celtibéricas en signario paleohispánico...

DÍAZ SANZ, María Antonia; JORDÁN CÓLERA, Carlos Benjamín, (2006), Dos Téseras de Hospitalidad Procedentes de Fitero (Navarra), en Paleohispánica, n. 6, Zaragoza, pp. 257-266.

ERRO AZPÍROZ, Juan Bautista (1806), Alfabeto de la lengua primitiva de España y explicación de sus más antiguos monumentos y medallas, imprenta de Repullés, Madrid, pp. $152-158$ y 161.

FATÁS CABEZA, Guillermo (1985), Una Tésera Cortonense, en Symbolae Lvdovico Mitxelena Septuagenario Oblatae (Vol. I), Anejo de Veleia, Series Maior, Melena, José L., Vitoria, pp. 425-431.

GÓMARA MIRAMÓN, Marta (2007), Una Inscripción Paleohispánica sobre una Cerámica Altoimperial en Cascante (Navarra), en Paleohispánica, n. 7, Zaragoza, pp. 263-268.

- (2006), Sondeo Estratigráfico en la Villa Romana de Campo Nuevo I (Cascante), en Trabajos de Arqueología de Navarra, n. 19, Pamplona, pp. 355-360.

GÓMEZ MORENO, Manuel (1949), Misceláneas. Historia-Arte, Arqueología. Primera Serie. La Antigüedad, Madrid, p. 275.

GONZÁLEZ RODRÍGUEZ, M. ${ }^{a}$ Cruz (1986), Las Unidades Organizativas Indígenas del Área Indoeuropea de Hispania, en Veleia, Anejo n. 2, Vitoria.

JORDÁN CÓLERA, Carlos Benjamín (2007), Estudios sobre el Sistema Dual de Escritura en Epigrafía no Monetal Celtibérica, en Paleohispánica, n. 7, Zaragoza, pp. 101-142.

- (2005-2006), Consideraciones Paleo-epigráficas a Propósito del Bronce Res, en Kalathos, n. 24-25, Teruel, pp. 475-486.

- (2004), Celtibérico, Zaragoza.

JIMENO MARTíNEZ, Alfredo (2005), Celtíberos. Tras la Estela de Numancia, Soria.

LOPERRÁEZ CORVALÁN, Juan Bautista (1778), Descripción Histórica del Obispado de Osma, Vol. II, edición facsímil de 1978, Madrid.

MEDRANO MARQUÉS, Manual; DÍAZ SANZ, María Antonia (2004), Fitero en la Historia. Desde el Eneolítico a la llegada del Islam, Ayuntamiento de Fitero - Gobierno de Navarra.

OLCOZ YANGUAS, Serafín (2007), Nueva Lectura de una Inscripción de una Inscripción Celtibérica de Numancia, en Revista de la Escuela Oficial de Idiomas de Soria, Soria, p. 47.

OLCOZ YANGUAS, Serafín; MEDRANO MARQUÉS, Manuel (2005-2007a), Tito Livio: Castra Aelia y el Límite Meridional del Ager Vasconum, Antes y Después de Sertorio, en $\mathrm{Na-}$ varra: Memoria e Imagen. VI Congreso de Historia General de Navarra, 19-22 Septiembre, 2006, Vol. I, Pamplona, pp. 55-75.

- (2005-2007b), Inscripciones Paleohispánicas, Turiaso, Uxama Argaela y las Guerras Cántabras, en Tvriaso, n. 18, Tarazona, pp. 199-214.

OLCOZ YANGUAS, Serafín; LUJÁN MARTÍNEZ, Eugenio; MEDRANO MARQUÉS, Manuel (2007), Inscripciones Paleohispánicas sobre Cerámica de La Rioja: Una Revisión de Conjunto, en Kalakorikos, n. 12, Calahorra, pp. 115-134.

PALOL SALELLAS, Pedro; VILELLA, José (1987), Clunia II: La Epigrafía de Clunia, en Excavaciones Arqueológicas en España, n. 150, Madrid.

PRÓSPER PÉREZ, Blanca M. ${ }^{a}$ (2008), El Bronce Celtibérico de Botorrita - I, en Pueblos, Lenguas y Escrituras en la Hispania Prerromana, n. 6, Pisa-Roma.

- (2007), Estudio Lingüístico del Plomo Celtibérico de Iniesta, Salamanca.

REMESAL RODRÍGUEZ, José. (1999), En Torno a una Nueva Tésera de Hospitalidad, en en «Pueblos, Lenguas y Escrituras en la Hispania Prerromana. Actas del VII Coloquio sobre Lenguas y Culturas Paleohispánicas", editado por Francisco Villar y Francisco Beltrán, Salamanca, pp. 595-603.

SIMÓN CORNAGO, Ignacio (2007), Muko - Kaiko, Relectura de K.9.1, en Paleohispánica, n. 7, Zaragoza, pp. 223-236.

TIRADO MARTíNEZ, José Antonio (2000), El Yacimiento del Solar Torres: Niveles de Ocupación Prerromano y Romano, Calahorra. 
TORIJA LÓPEZ, Alicia; BAQUEDANO BELTRÁN, Isabel (2007), Las Téseras de la Colección Cerralbo. Viejas Conocidas, Nuevas Perspectivas, en Paleohispánica, n. 7, Zaragoza, pp. 269-336.

UNTERMANN, Jürgen (1997), Monumenta Linguarum Hispanicarum, tomo IV, Die Tartesischen, Keltiberischen und Lusitanischen Inschriften, Wiesbaden.

VELAZA FRÍAS, Javier (1999), Balance Actual de la Onomástica Personal Celtibérica, en Pueblos, Lenguas y Escrituras en la Hispania Prerromana. Actas del VII Coloquio sobre Lenguas y Culturas Paleohispánicas, editado por Francisco Villar y Francisco Beltrán, Salamanca, pp. 663-683.

VICENTE REDÓN, Jaime; PUNTER GÓMEZ, M. ${ }^{a}$ Pilar; ESCRICHE JAIME, Carmen; HERCE SAN MIGUEL, Ana Isabel (1993), Las Inscripciones de la "Casa de LIKINE» (Caminreal, Teruel), en Lengua y Cultura en la Hispania Prerromana, Salamanca, pp. 747772.

WATTENBERG, Federico (1963), Las Cerámicas Indígenas de Numancia, Madrid. 